British physicians in the next year or two but should interpret this in economic terms and not in those of British disinterest. Long live the International Study Group of Diabetes in Children and Adolescents!

JAMES W FARQUHAR

University Department of Child

Life and Health

Roval Hospital for Sick Children,

Edinburgh

' Farquhar, $\mathrm{J}$ W, in Clinics in Endocrinology and Metabolism, No 5, Aspects of Neonatal Metaboli

${ }^{2}$ Farquhar, J W, Notes for the Guidance of Parents Diabetic Children, 2nd edn. Edinburgh, Churchil Diabetic Children

Farquhar, J W, International Diabetes Federation Bulletin, 1976, 21, October, p 6.

\section{Lumbar epidural analgesia in labour}

SIR,-Dr I D Hoult and his colleagues (1 January, p 14) focus attention on an important question concerning the safety of epidural block. Does an increased incidence of forceps delivery, and especially with Kielland's forceps, entail an inherent risk to the baby or mother? The unequivocal answer must be yes; interference may always lead to morbidity. However, there is room for substantial qualification.

A comment must be made on the technical difficulty of the use of Kielland's forceps. Dr Hoult and his colleagues discuss only two fetal presentations at delivery, the occipitoanterior and the occipitoposterior positions. Since malposition has not been clearly defined (whether the occiput was posterior or lateral) the apparent high incidence of malposition could be interpreted as a failure to recognise that the head normally engages in the transverse position, and in the presence of epidural analgesia rotation commonly occurs only at the outlet. It seems to us that a high incidence of rotation from the transverse position might be expected if the second stage is curtailed before the head has descended to lower levels. Our own experience suggests that assisted rotation from the transverse position is required more frequently than from the posterior position. Otherwise the implication is that in some way epidural block actively favours posterior rotation of the occiput, which we would strongly contest. The more serious malpresentations of deep transverse arrest (as opposed to transverse position) and the assisted persistent occipitoposterior position should have been separately presented. The implications in terms of fetal and materna damage of an uncomplicated rotation from a transverse position are very different from the more serious, disproportion-induced malpresentations. (In our experience most instances of malrotation after epidural block can be easily turned). Difficulties with Kielland's forceps arise from cephalopelvic disproportion and are not related to the method of pain relief. ${ }^{1}$ The skill of the operator is fundamental in making a decision as to whether forceps delivery can be performed safely.

We have found no evidence of increased perinatal mortality after epidural block. In fact, there may even be a protective effect on the premature infant. ${ }^{2}$ The question of increased morbidity is far more difficult to quantify, although Dr Hoult and his colleagues partly answer that point since none of the 50 babies delivered by Kielland's forceps required admission to their special care baby unit. There is clearly no substitute for adequate operative experience.

We completely agree that the mother should know beforehand of any likely complication from epidural block. It has been our practice for some years, in the mothercraft class or labour ward, to tell every mother who chooses an epidural block that the incidence of forceps delivery is about 3-4 times more than after other forms of pain relief. (We also mention the headache which can occur after accidenta lumbar puncture.) Twenty-five per cent of our patients elect to have epidural block.

Since there are no unequivocally proved medical indications for epidural block other than excellent pain relief (although there are relative advantages) epidural block must be carried out and managed expertly. We believe that with nursing and medical staff trained to standards appropriate for a well-organised obstetric unit there should be no measurable additional risk to the mother or her baby. Contrary to the apparent practice of Dr Hoult and his colleagues we believe that the primary indication for epidural block is the request of the well-informed mother for complete pain relief.

Bryan Hibbard
James F Pearson B Weaver
Sheila M Walker Michael Rosen

Departments of Obstetrics and

Gynaecology and Anaesthetics,
Welsh National School of Medicine

Davidson, A C, et al, British fournal of Obstetrics and Gynaecology, 1976, 83, 4

${ }^{2}$ David, H, and Rosen, M, Anaesthesia, 1976, 31, 1054.

\section{Chemotherapy for varicella-zoster}

\section{infections}

SIR,-Your leading article (18 December, p 1466) shows quite clearly the difficulties of treating varicella-zoster, even with the advent of second-generation antiviral agents. It shows that even in life-threatening cases there are no more than anecdotal reports of successful treatment with adenosine arabinoside (ara-A). I recall that similar encouraging reports were made about intravenous idoxuridine (IDU) in the treatment of herpes simplex encephalitis $^{2}$ until the Boston controlled trial ${ }^{3}$ had to be abandoned owing to therapeutic failure and unacceptable side effects. In their book ${ }^{4}$ JuelJensen and MacCallum recommend the use of cystosine arabinoside (ara-C) and ara-A for the treatment of severe zoster without reference to clinical trials of these compounds.

One cannot leave unchallenged the conclusions in your final paragraph regarding treatment of "mild" cases of zoster. Most patients are incapacitated and even in the relatively young the symptoms can be protracted and temporarily disabling. Herpes zoster should be treated not only for the pain but also to minimise or prevent scarring and posthepatic neuralgia. You recommend treatment of "mild" cases of zoster with a $40 \%$ o solution of IUD in dimethylsulphoxide (DMSO). This product is not manufactured by any pharmaceutical company in the United Kingdom or in the rest of the world to my knowledge. If applied by the technique recommended by Juel-Jensen and MacCallum ${ }^{4}$ it is extremely expensive, may cause inflammatory and even necrotic skin changes, and in practice can be used properly only under careful medical supervision in hospital. In 1974 I reported in your pages $^{5}$ the results of a randomised double-blind trial assessing $5^{\circ}$ IDU in DMSO in 118 patients. I concluded that this solution had as great an effect on zoster as $25^{\circ}$, IDU. In 1975 Simpson $^{6}$ compared $5^{\circ}$ and $40^{\circ}$. IDU in DMSO in 50 cases and showed that both produced equal benefit; $5^{\circ}$. IDU in DMSO is available on prescription (Herpid; WB Pharmaceuticals), but $40^{\circ}$. IDU in DMSO cannot be recommended for routine domiciliary treatment of mild zoster.

RODNEY DAWBER

Department of Dermatology,

Slade Hospital and

Radcliffe Infirmary,

Nolan, D C, et al, New England fournal of Medicine,

$1970,282,10$.
Juel-Jensen, B E, and MacCallum, F O, Herpes
Simplex, Varicella and Zoster, p 154. London, Simplex, Varicella and Zoster, p 154. London. Heinemann, 1972.

Boston International Virus Study Group, New England fournal of Medicine, 1975, 292, 599.

Simplex, B E, and MacCallum, F O, Herpe Heinemann, 1972

Dawber, R, British Medical fournal, 1974, 2, 526

' Simpson, J R, Practitioner, 1975, 215, 226. 1, 737

\section{Self-poisoning with drugs}

SIR,-After all, the rise and rise of selfpoisoning - in the news at least once a yearcould be a paper tiger. Just frighten it and watch how it shrinks. Unlike last year's first claim of the monster's weakness, ${ }^{1}$ which unfortunately didn't stand up to closer scrutiny, ${ }^{2}$ this time there are impressive figures to support the claim. The good news comes from Sheffield. In recording the familiar increase in the past 20 years, Dr D I R Jones (1 January, p 28) found that "the only thing that had a demonstrably favourable effect on the rate of self-poisoning was the threatened withdrawal of the emergency services." Is it now the time to pay tribute to the junior hospital doctors who, by embarking on industrial action in December 1975, unknowingly set up the natural experiment?

Recognising that his data (table II) showed a seasonal variation Dr Jones states that in December 1975 the number of admissions for self-poisoning were "abnormally low"; from this he concluded that the junior doctors' industrial action was the probable reason for the drop. But such a claim can be justified only if the observed reduction (if any) can be shown to be independent of seasonal variation as well as statistically significant. As the author has included a tabulation of admissions for each month in the past six years an obvious discrepancy between his figures and their interpretation must be pointed out.

Dr Jones claims that the pronounced seasonal variation was "inconstant." A closer look at table II, however, does not bear this out. Even before the crucial year (1975) it can be observed that there was a trend towards high numbers in the summer and low numbers in the winter; spring and autumn were intermediate, the former having a higher average rate than the latter. If one calculates average daily numbers for each season it can be shown that winter has the lowest rank in four of the five years, while summer has the highest rank for the same number of years. A comparison of each observed monthly number of admissions with the expected number over the same period produces significant differences in 12 out of the 60 months in question. Four out of five significant drops concern winter months, 